\title{
A Comparison between Channelled and Unchannelled Balcony Spill Plumes
}

\author{
Roger Harrison BSc, MEFE, PhD, CPhys and \\ Michael Spearpoint BSc, MSc, PhD, CEng, MIFE, MSFPE* \\ Department of Civil and Natural Resources Engineering, \\ University of Canterbury, New Zealand.
}

\begin{abstract}
The use of channelling screens in smoke management design can reduce balcony spill plume entrainment by restricting smoke spread under the balcony. The omission of channelling screens can gave rise to a greater lateral extent resulting in a change in the entrainment conditions. This work provides new experimental data using physical scale modelling to enable a comparison between channelled and unchannelled plumes. The lateral spread for unchannelled plumes was found to be dependent upon the velocity of the flow from the fire compartment opening. The measured entrainment for plumes without screens was greater than that from equivalent plumes with screens and the relative difference in entrainment increased as the width of the fire compartment opening decreased. A simple approximation to predict entrainment for unchannelled plumes from wide fire compartment openings is proposed.
\end{abstract}

\section{INTRODUCTION}

The design of smoke management systems requires appropriate entrainment calculation methods to predict the volume of smoky gases produced in a fire in order to determine the required exhaust fan capacity or ventilator area for a design clear layer height. Consideration is often given to entrainment of air into a smoke flow from a compartment opening that subsequently spills at a balcony edge and then rises into an adjacent atrium void. This type of thermal plume is commonly known as a balcony spill plume (see Figure 1). If the smoke flow from the compartment opening is allowed to pass unrestricted under a balcony, it will spread laterally. The smoke flow will spill at the balcony edge (i.e. the spill edge) and rise into the atrium space with a large surface area over which entrainment of air occurs. Spill plumes that do not include entrainment into the ends of the plume are known as two-dimensional (2-D) plumes and those that include end entrainment are known as three-dimensional (3-D) plumes.

Published as Harrison R, Spearpoint M. A comparison between channelled and unchannelled balcony spill plumes, Building Serv Eng Res Technol, 31(3), 265-277. doi:10.1177/0143624410368242

\footnotetext{
* Corresponding author: michael.spearpoint@canterbury.ac.nz; tel.: +64 (0)3 3642237
} 


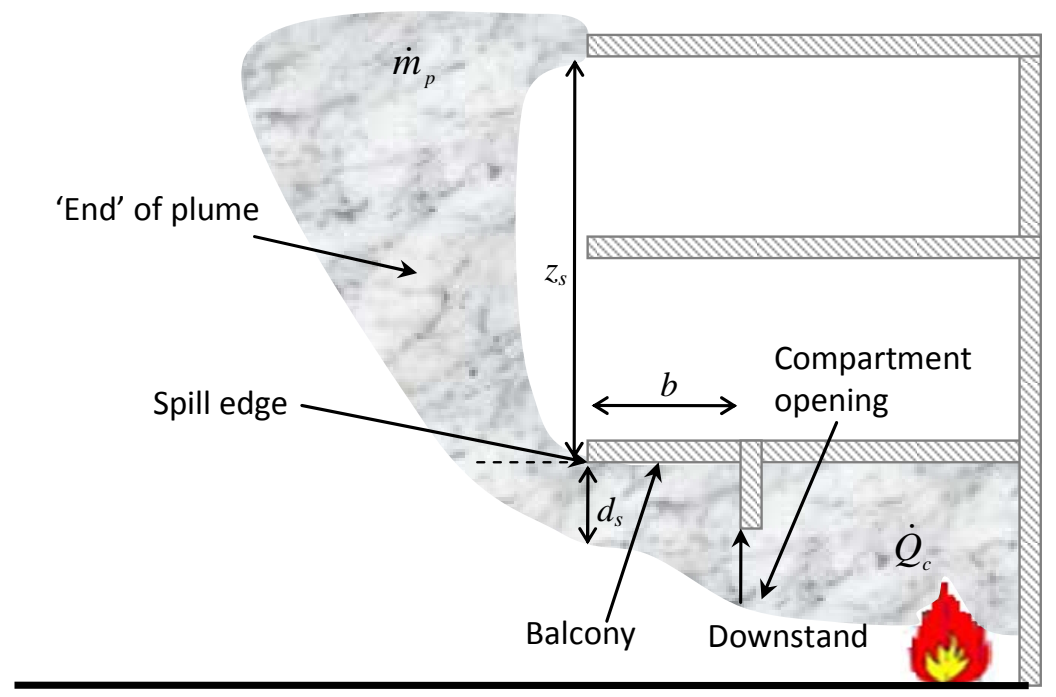

Section

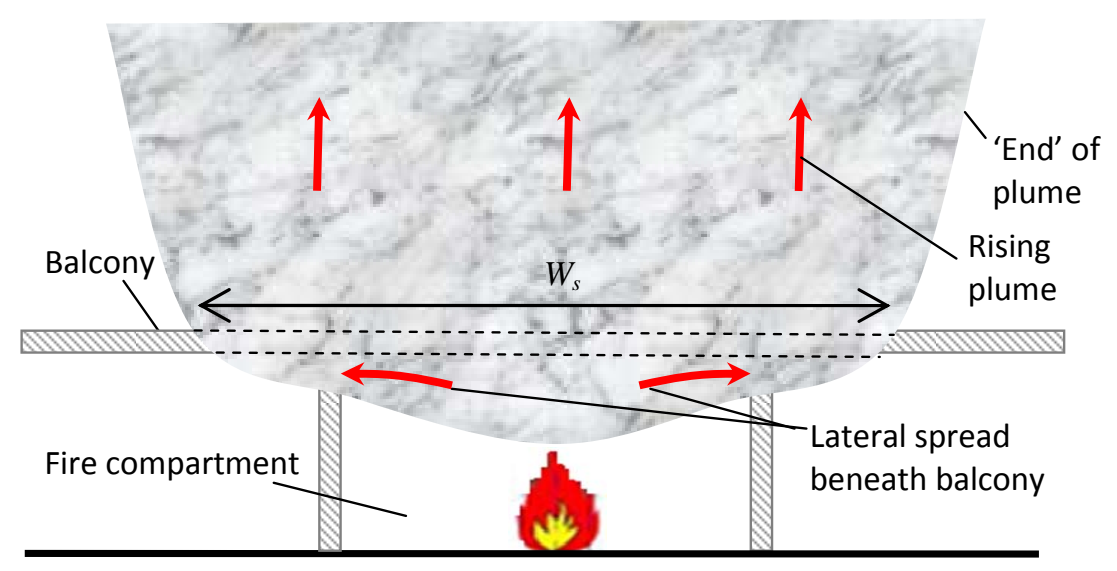

(a)

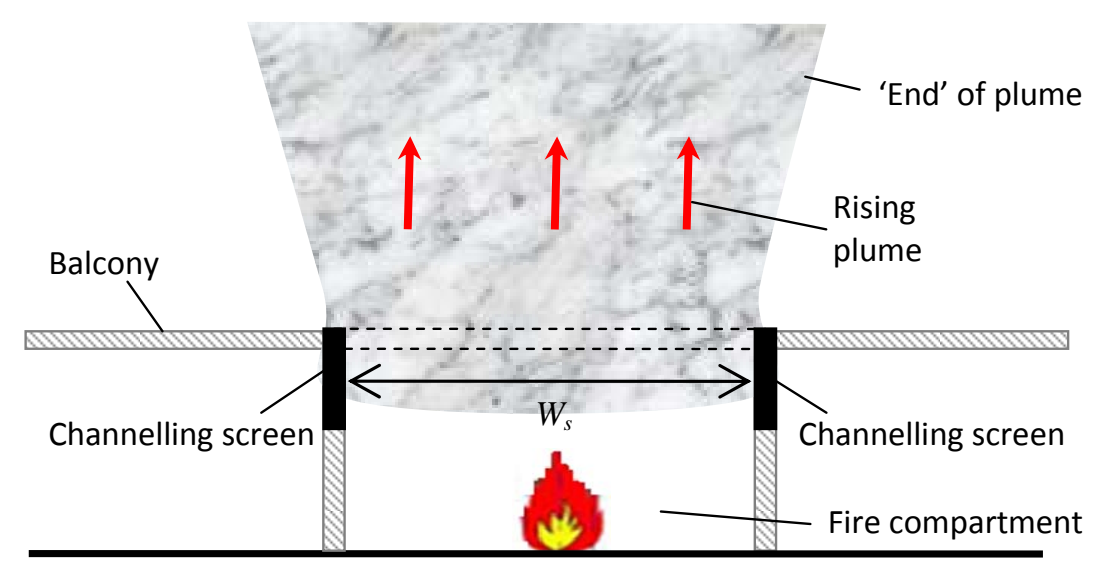

(b)

Figure 1: Schematic drawing of a typical 3-D balcony spill plume with and without channelling screens (a) Front view - no channelling screens below balcony, (b) Front view - channelling screens below balcony. 
The amount of entrainment can be reduced by restricting the ability of the smoke flow to spread laterally with the use of channelling screens beneath the balcony to 'channel' the flow to the balcony edge [1]. Entrainment of air into channelled 2-D and 3-D balcony spill plumes has recently been characterised by Harrison and Spearpoint [2] from an extensive series of physical scale model experiments. Entrainment into unchannelled balcony spill plumes is not so well understood. A very limited data set obtained from $1 / 10^{\text {th }}$ physical scale model experiments by Hansell et al. [3] was subsequently analysed by Law [4] to give simplified design guidance for this scenario. This guidance is given by CIBSE [5] and remains in the current version of NFPA 92B [6] following further full scale experiments by Lougheed et al. [7]. This paper provides new experimental data for the unchannelled balcony spill plume entrainment using physical scale modelling by varying the width of the fire compartment opening, fire size and height of rise of plume. These data complement the Harrison and Spearpoint [2] data for channelled plumes and enable a comparison between these channelled and unchannelled plumes to be made.

The approach of physical scale modelling is well established and has been used in many studies of smoke movement in buildings. The approach described in this article was primarily developed at the Fire Research Station in the UK [8, 9] and typically takes the form of reduced scale fires within a physical model. The approach is also described by Klote and Milke [10] and is included in NFPA 92B [6]. Measurements are generally made of temperature, velocity and gas concentrations, in addition to visual observations. To ensure that the results can be extrapolated to full scale, the physical scale model used in this study was designed to meet the scaling laws set out by Thomas et al. [8]. This is effectively a modified Froude number scaling and requires that the equivalent flows are fully turbulent on both full and model scale.

\section{THE EXPERIMENTS}

\subsection{The physical scale model}

The $1 / 10^{\text {th }}$ physical scale model used (see Figure 2) was the same as that used by Harrison and Spearpoint [2] for channelled plumes. A detailed description of the model is given by Harrison and Spearpoint. In summary, the model simulated a fire within a room adjacent to an atrium void and consisted of two main units, a fire compartment to generate the plume and a smoke collecting hood to measure entrainment. A $0.3 \mathrm{~m}$ broad balcony was attached to the top of the fire compartment opening. The Harrison and Spearpoint [2] experiments utilised channelling screens (either 0.2 or $0.3 \mathrm{~m}$ deep) located in line with the walls of the fire compartment opening. The width of the fire compartment opening was reduced by inserting walls of equal width at either end of the open face. The inserted walls had widths of $0.1,0.2,0.3$ or $0.4 \mathrm{~m}$ depending upon the opening geometry required. The model was designed such that the walls of the smoke collecting hood could freely move in a vertical direction within a supporting steel frame. This enabled the base of each wall to be moved independently to just below the base of the desired height of rise of plume allowing unrestricted fresh air to be entrained into the rising plume. A section of steel reinforcing mesh was hung next to one wall of the collecting hood to 
provide a point of reference for visual observations for the plume behaviour. The individual grid size of the mesh was 75 by $75 \mathrm{~mm}$.

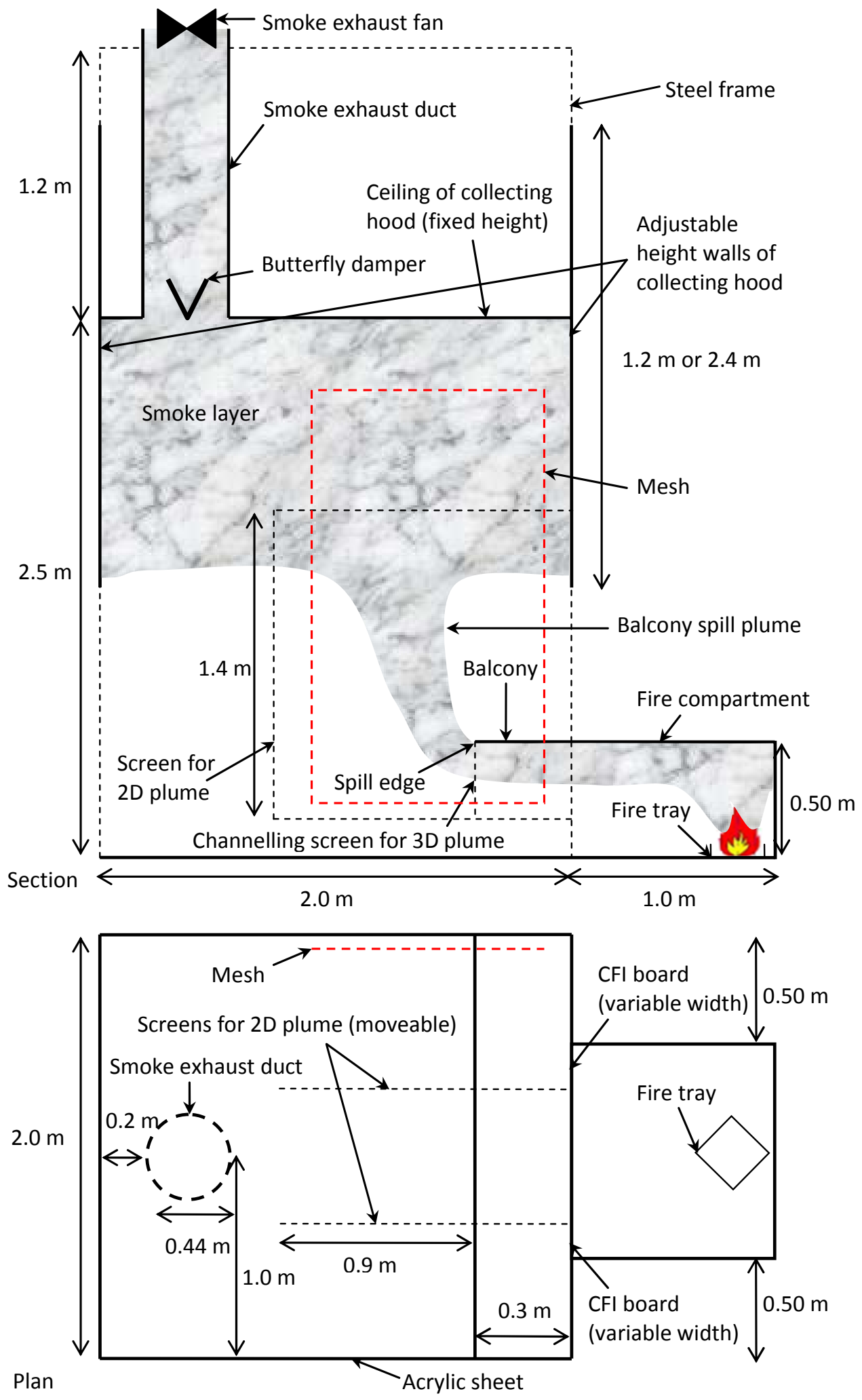

Figure 2: Schematic drawing of the $1 / 10^{\text {th }}$ physical scale model. 
A steady fire source was generated by supplying Industrial Methylated Spirits (IMS) into a metal tray within the fire compartment at a controlled and measured rate. The total heat release rate of the fire was determined from the heat of combustion and the volume flow rate of the fuel. The hot gases from the fire were visualised by injecting smoke from a commercial smoke generator into the fire compartment.

The mechanical smoke exhaust system from the hood consisted of a $0.44 \mathrm{~m}$ diameter bifurcated fan attached to the hood exhaust vent using temperature resistant flexible ducting. The fan speed was controllable, which enabled different exhaust rates, and hence, variation in the height of rise of the plume to be examined. The vent within the smoke exhaust hood contained a 'butterfly' damper which could be adjusted to alter the size of the vent from the hood. This was necessary for those experiments which required very low smoke exhaust rates from the hood.

\subsection{Instrumentation and measurements}

Gas temperatures were measured using $0.5 \mathrm{~mm}$ diameter K-type thermocouples positioned at various locations in the model as follows: two columns of 15 thermocouples within the smoke collecting hood; one column of 18 thermocouples located centrally beneath the balcony edge; an array of 23 thermocouple across the balcony edge, projecting $10 \mathrm{~mm}$ below the edge; an array of five thermocouples in the throat of the exhaust vent and one thermocouple located centrally within the smoke exhaust duct, $5.0 \mathrm{~m}$ downstream of the exhaust vent. A perforated gas sampling tube was located across the horizontal diameter of the exhaust duct approximately $5.0 \mathrm{~m}$ downstream of the vent in the smoke collecting hood. This enabled measurement of the $\mathrm{CO}_{2}$ gas concentration of the gas flow in the duct to be made using an infra red gas analyser (Siemens, Ultramat 6 , accuracy $\pm<1 \%$ ). The mass flow rate of gases entering the buoyant gas layer in the smoke collecting hood and therefore leaving the hood, was found by using a $\mathrm{CO}_{2}$ tracer gas technique and calculation method described by Marshall [9]. The mass flow rate and convective heat flow rate of layer flow below the spill edge was not determined for unchannelled flows as lateral spread below the balcony caused the flow to become diffuse and non-uniform. Therefore, it was not practical to utilise velocity and temperature measurements below the balcony edge (as used by Harrison and Spearpoint [2] for channelled plumes) due to the excessive number of measurements points required to characterise the flow. Visual observations of each test were carried out, including the plume behaviour and the smoke layer depth below the spill edge and within the collecting hood.

\subsection{Parameter variation}

A total of 85 experiments were carried out to examine entrainment into unchannelled balcony spill plumes. These complement the 97 experiments for channelled plumes by Harrison and Spearpoint [2]. The majority of experiments examined plumes generated from fires with a total heat release rate $\left(\dot{Q}_{t}\right)$ of 5 and $10 \mathrm{~kW}$ (1.6 and $3.2 \mathrm{MW}$ full scale equivalent), as the lateral spread beneath the balcony for $15 \mathrm{~kW}$ fires (4.7 MW full scale equivalent) was so great that gases could not be collected in the hood above, thus, these experiments were not continued. The width of the fire compartment opening $\left(W_{o}\right)$ 
was varied with widths of $0.2,0.4,0.6,0.8$ and 1.0 m examined. Varying the total heat output of the fire in turn varied the mass flow rate, convective heat flow rate and depth of the gas layer flow below the spill edge. The conditions studied were chosen to provide a range of layer flows below the spill edge (i.e. from relatively cool, shallow and wide layer flows to hot, deep and narrow flows) which could conceivably be generated from a range of possible geometries upstream of the spill edge. The height of rise of plume above the spill edge $\left(z_{s}\right)$ was also varied with five different heights examined between 0 to $0.95 \mathrm{~m}$. The cross sectional area of the smoke collecting hood $(2.0 \mathrm{~m}$ by $2.0 \mathrm{~m})$ and the breadth of the balcony $(0.3 \mathrm{~m})$ were fixed for the series of experiments.

\section{RESULTS AND DISCUSSION}

\subsection{The 3-D Balcony Spill plume with channelling screens}

Harrison and Spearpoint [2] have characterised entrainment into channelled 3-D balcony spill plumes. In summary, the work showed that the rate of entrainment is specifically dependent on the characteristics of the layer flow below spill edge, particularly in terms of $W_{s}$ and $d_{s}$, such that plumes generated from narrow, deep layer flows entrain air at a greater rate with respect to height compared to plumes generated from wide, shallow layers. A new simplified design formula has been proposed by developing a general empirical expression to explicitly describe the entrainment of air into the free ends of the plume. This simplified formula can be applied more generally compared to currently available formulae and is given by,

$\dot{m}_{p, 3 D}=0.16 \dot{Q}_{c}^{1 / 3}\left(W_{s}^{2 / 3}+1.56 d_{s}^{2 / 3}\right) z_{s}+1.34 \dot{m}_{s}$

Equation 1 was determined empirically from data which exhibited linearity, however, it is expected that at higher heights of rise of plume, the effect of end entrainment will cause the plume to be more axisymmetric in nature and linearity will no longer apply, hence, there will be a limit to its use. This limit has been developed by Harrison [11] by determining a general expression describing the height at which Equation 1 becomes equivalent to an axisymmetric plume formula (i.e. according to $z_{s}^{5 / 3}$ ). Therefore, Equation 1 applies when $z_{s} \leq z_{\text {trans }}$, such that,

$$
Z_{\text {trans }}=3.4\left(W_{s}^{2 / 3}+1.56 d_{s}^{2 / 3}\right)^{3 / 2}
$$

\subsection{The 3-D Balcony Spill plume without channelling screens}

\subsubsection{Plume behaviour}

Figures $3 a$ to $3 c$ show a comparison between channelled and unchannelled plumes from a wide, intermediate and a narrow width compartment opening respectively (i.e. $W_{o}=1.0,0.6$ and $0.2 \mathrm{~m}$ ). Without channelling screens there was lateral spread of the layer flow below the balcony which was not well defined. The depth of this layer flow was not uniform and was generally deeper at the centreline of the flow and shallower near the extremities. The shallow layer flow at the extremities tended to be stagnant in nature and lacked sufficient buoyancy to rise as part of a plume into the collecting hood 
above due to the cooling of these gases after lateral spread. The spread of the flow below the balcony subsequently gave rise to plumes with a greater lateral extent above the spill edge compared to plumes generated with the use of channelling screens. The relative increase in the lateral extent of the rising plume (when compared to $W_{o}$ ) increased as $W_{o}$ decreased (which also occurred when $\dot{Q}_{t}$ increased).

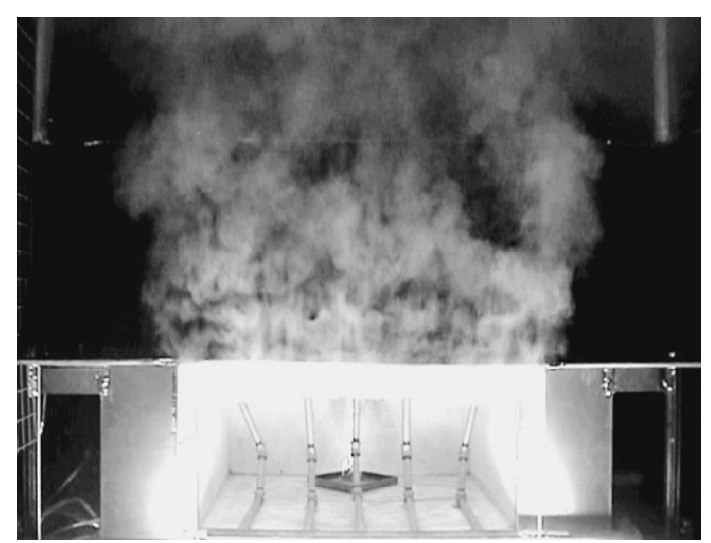

i) with channelling screens

(a)

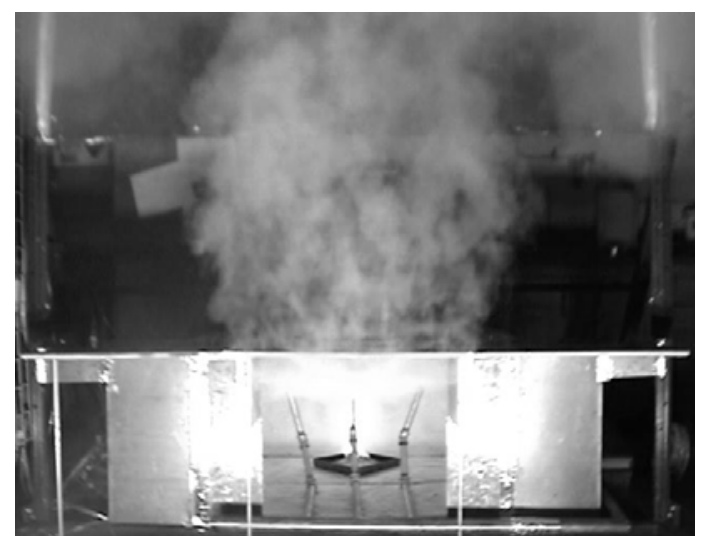

i) with channelling screens

(b)

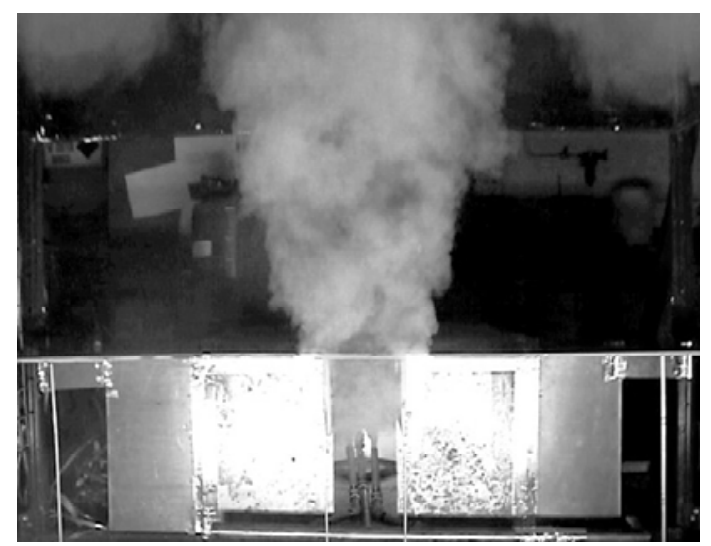

i) with channelling screens

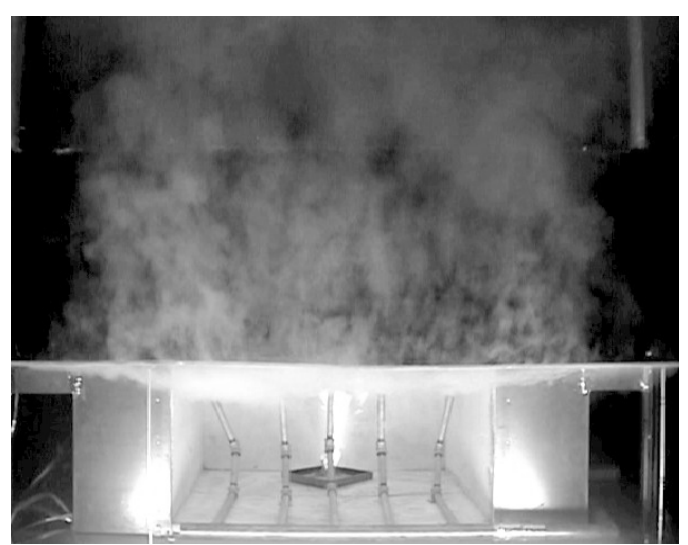

ii) without channelling screens

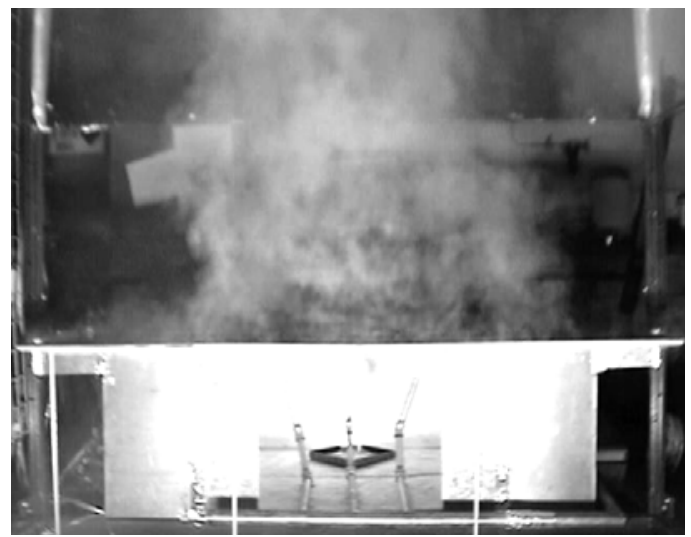

ii) without channelling screens

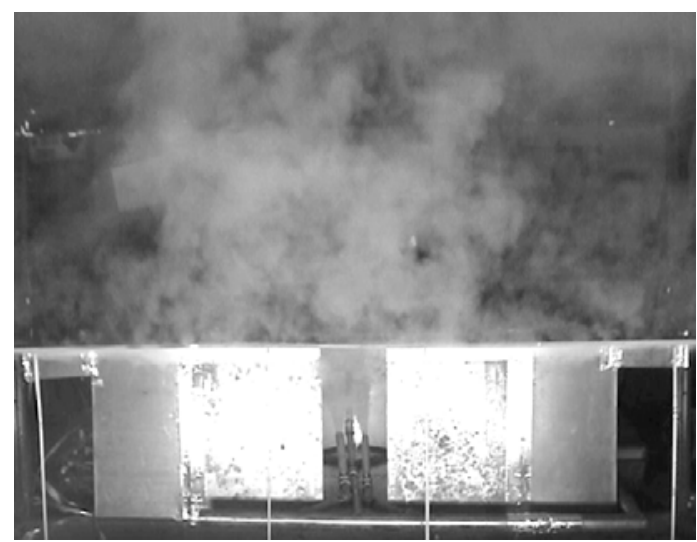

ii) without channelling screens

(c)

Figure 3: Plume behaviour with and without channelling screens for (a) wide opening ( $\left.W_{o}=1.0 \mathrm{~m}\right)$, (b) intermediate width opening $\left(W_{o}=0.6 \mathrm{~m}\right)$, (c) narrow opening $\left(W_{o}=0.2 \mathrm{~m}\right)$. 
To quantify the increase in the lateral extent of the plume for flows without channelling screens, visual observations were made of the lateral extent of the flow below the spill edge $\left(W_{s}\right)$ for each $W_{o}$ and $\dot{Q}_{t}$ examined (see Table 1). The values of $W_{s}$ in Table 1 specifically apply to the region of the flow below the spill edge that contained sufficient buoyancy to rise as a plume and did not include the stagnant gases at the extremities. It is interesting to note that the absolute values of $W_{s}$ in Table 1 remain reasonably constant for each $\dot{Q}_{t}$ examined with respect to changes in $W_{o}$. However, Table 1 shows that the ratio of $W_{s} / W_{o}$ increases significantly as $W_{o}$ decreases (and as $\dot{Q}_{t}$ increases). For the conditions studied, $W_{s}$ was approximately 35 to $70 \%$ greater than $W_{o}$ for flows from a wide opening (i.e. $W_{o}=1.0 \mathrm{~m}$ ), however, for flows from a narrow opening (i.e. $W_{o}=0.2 \mathrm{~m}$ ) $W_{s}$ was approximately 6 to 9 times greater than $W_{o}$. The extensive amount of lateral spread below the balcony for flows from a narrow opening gave rise to subsequent plumes that were particularly complex and relatively unstable in nature compared to plumes from wider openings. The amount of lateral spread below the balcony is dependent upon the velocity of the gas flow emerging from the fire compartment opening which increases when $W_{o}$ decreases and $\dot{Q}_{t}$ increases. An increase in velocity in all components of the flow from the compartment opening (both parallel and perpendicular to the opening) will cause an increase in lateral spread (see Figure 4).

Table 1: Visually observed values of $W_{s}$ for flows without screens.

\begin{tabular}{cccc}
\hline $\begin{array}{c}\dot{Q}_{t} \\
(\mathrm{~kW})\end{array}$ & $\begin{array}{c}W_{o} \\
(\mathrm{~m})\end{array}$ & $\begin{array}{c}W_{s} \\
(\mathrm{~m})\end{array}$ & $W_{s} / W_{o}$ \\
\hline 5.0 & 1.0 & $1.35 \pm 0.10$ & 1.35 \\
10.0 & 1.0 & $1.70 \pm 0.10$ & 1.70 \\
5.0 & 0.8 & $1.30 \pm 0.10$ & 1.60 \\
10.0 & 0.8 & $1.60 \pm 0.10$ & 2.00 \\
5.0 & 0.6 & $1.30 \pm 0.10$ & 2.20 \\
10.0 & 0.6 & $1.70 \pm 0.10$ & 2.80 \\
5.0 & 0.4 & $1.35 \pm 0.10$ & 3.40 \\
10.0 & 0.4 & $1.75 \pm 0.10$ & 4.40 \\
5.0 & 0.2 & $1.35 \pm 0.20$ & 6.75 \\
10.0 & 0.2 & $1.70 \pm 0.20$ & 8.50 \\
\hline
\end{tabular}

Although the absolute values of $W_{s}$ in Table 1 remain reasonably constant for each $\dot{Q}_{t}$ examined with respect to changes in $W_{o}$, the nature of the plumes rising above the edge were different when considering the temperature profiles across the flow just below the spill edge. Figure 5 shows a comparison of typical temperature profiles across the spill edge, $10 \mathrm{~mm}$ below the edge, for a flow from a wide, intermediate and narrow width compartment opening respectively without the use of channelling screens (i.e. $W_{o}=1.0,0.6$ and $0.2 \mathrm{~m}, \dot{Q}_{t}=5 \mathrm{~kW}$ ). 


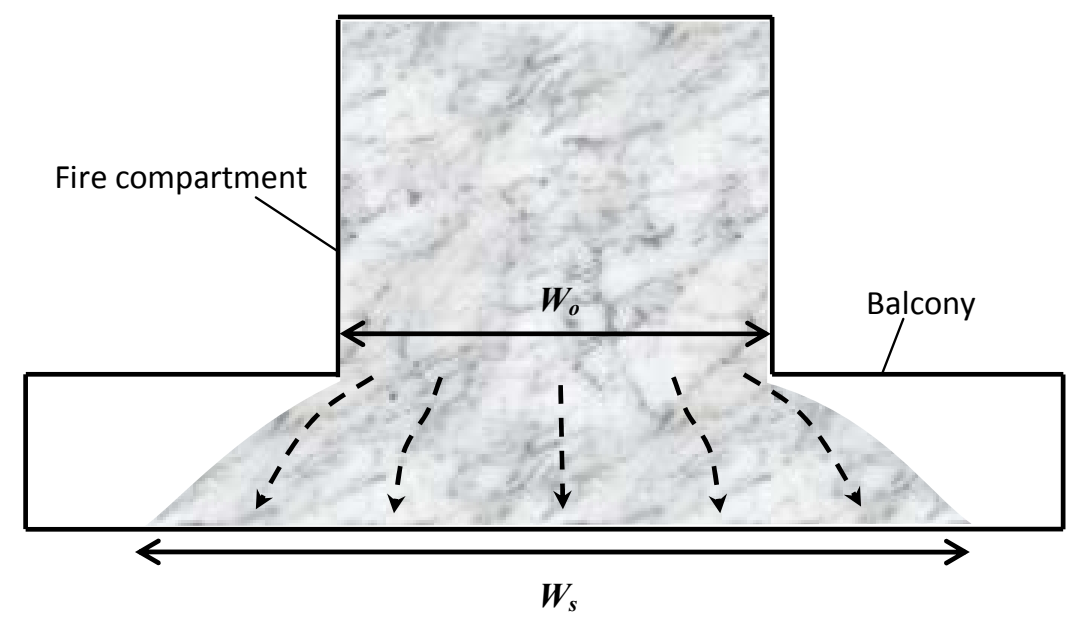

(a)

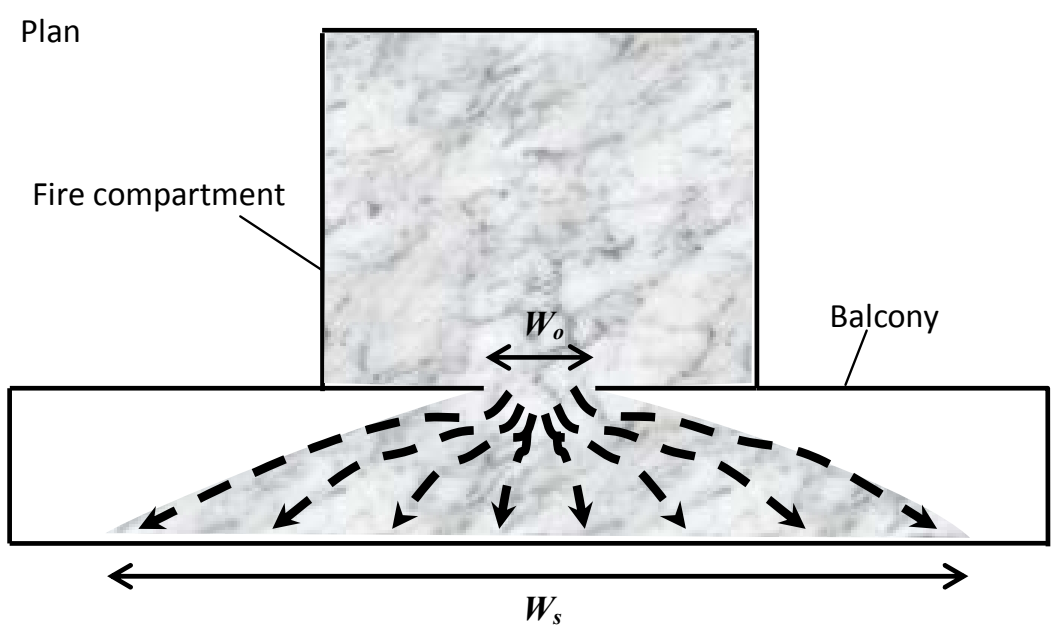

(b)

Figure 4: Schematic drawing of the lateral spread below the balcony without channelling screens (a) flow without channelling screens from a wide compartment opening (i.e. $W_{o}=1.0 \mathrm{~m}$ ). (b) flow without channelling screens from a narrow compartment opening (i.e. $W_{o}=0.2 \mathrm{~m}$ ).

Figure 5 shows that the temperature profiles for each $W_{o}$ examined approach ambient at a similar distance from the centreline of the flow consistent with the visual observations of $W_{s}$. However, the nature of these profiles for each $W_{o}$ are different. The profile across the flow from a wide opening was reasonably uniform for majority of the flow (apart from at the extremities), but for a narrow opening the profile is characterised by a single peak at the flow centreline. An intermediate width opening gives rise to a profile part way between that from a wide and narrow compartment opening. As the plumes generated without channelling screens did not generally provide uniformity in terms the depth and temperature across the layer flow below the balcony edge, any subsequent plume will violate the fundamental assumption made for all current empirical calculation methods. 


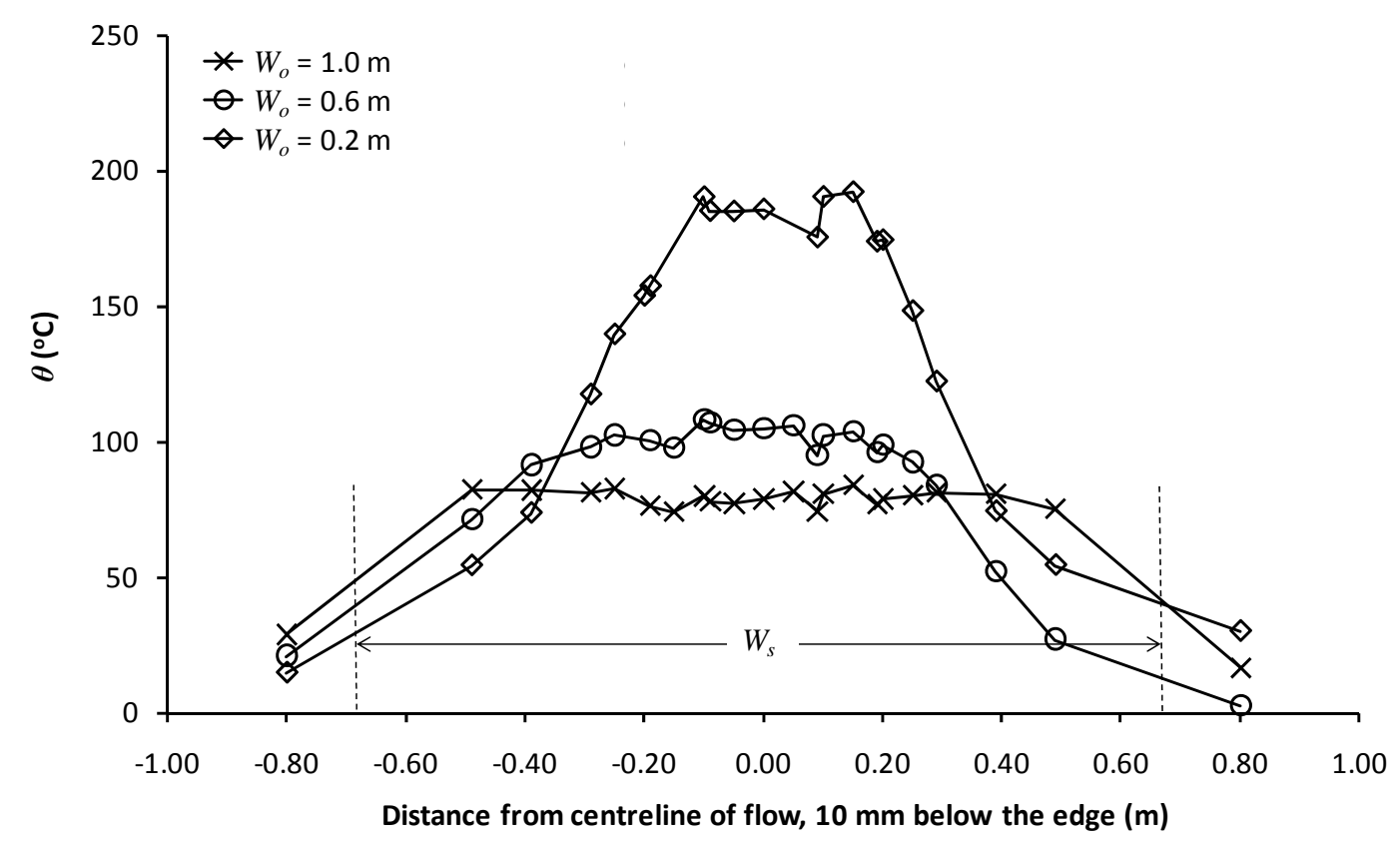

Figure 5: Typical temperature profiles across the spill edge without screens.

Figure 6 shows a comparison of the plume behaviour both with and without screens from a side view. This behaviour was generally typical for plumes generated from the range of fire compartment opening widths examined. Figure 6 shows that the plume generated without screens below the balcony is less well defined compared to an equivalent plume produced with screens. Without channelling screens the plume tended to curl back above the spill edge to cause smoke contamination local to the area above the balcony in line with the fire compartment opening. In addition, the relatively stagnant smoke at the extremities of the flow below the balcony caused smoke to accumulate just above the balcony edge. This stagnant smoke was observed to be subsequently entrained back towards the rear of the rising plume via the area above the balcony causing further smoke contamination. This plume behaviour is an important consideration for the design of smoke management systems, particularly when addressing the tenability of the smoke local to the area just above the balcony, which could be designated as an escape route. This study has not examined the tenability of the smoke contamination above the balcony. 


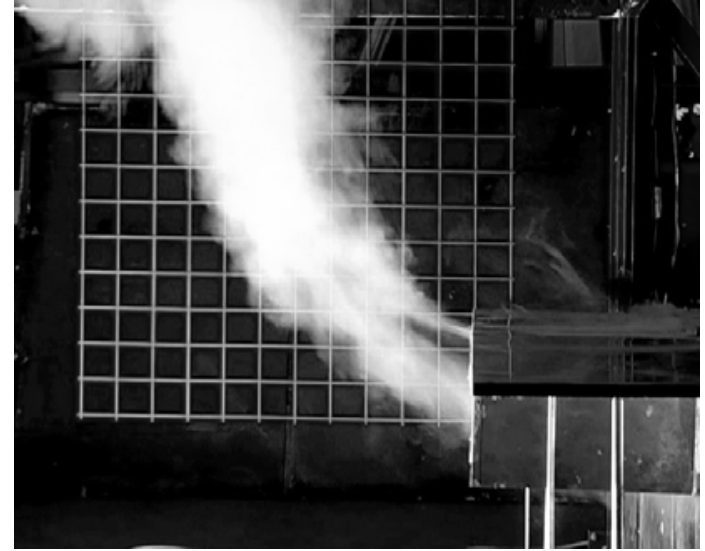

(a)

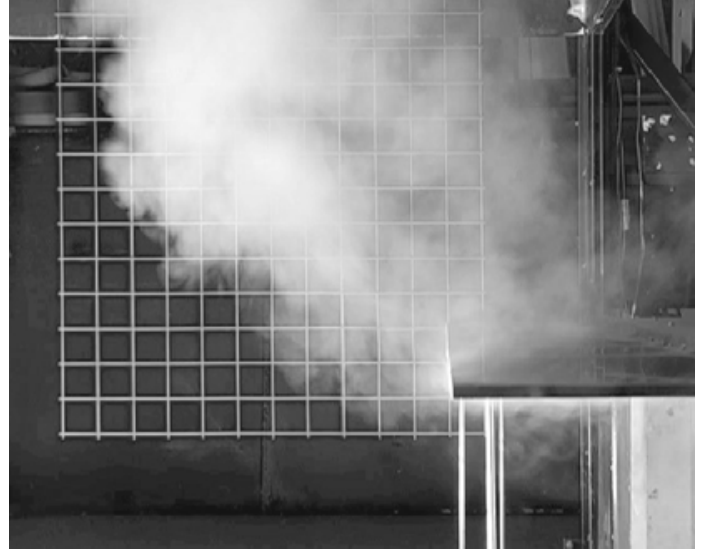

(b)

Figure 6: Comparison of typical plume behaviour with and without screens from a side view (a) with channelling screens, (b) without channelling screens.

\subsubsection{Entrainment analysis}

Since the characteristics of the layer flow below the spill edge (i.e. $\dot{Q}_{c}, \dot{m}_{s}$ and $d_{s}$ ) could not be directly measured in the experiments without channelling screens, the methods used by Harrison and Spearpoint [2] for the entrainment analysis of channelled plumes cannot be applied here. Therefore, in an attempt to quantify entrainment into plumes produced without screens, Figure 7 shows a direct comparison of the measured plume mass flow rates $\left(\dot{m}_{p, 3 D}\right)$ for equivalent plumes with and without screens below the balcony, using the data for channelled plumes analysed by Harrison and Spearpoint [2] and given by Harrison [11]. Figure 7 shows little difference in entrainment between plumes generated with or without screens for values of $\dot{m}_{p, 3 D}$ less than $0.10 \mathrm{~kg} \mathrm{~s}^{-1}$. However, these data were measured at $Z_{s}=0$ and describe the entrainment below the height of the spill edge. Therefore, it appears that the only significant difference in the flow of gases below the spill edge, with or without screens, is how these flows are distributed below the balcony (in terms of width and depth).

Figure 7 shows that for values of $\dot{m}_{p, 3 D}$ greater than $0.10 \mathrm{~kg} \mathrm{~s}^{-1}$ obtained at $z_{s}>0$, the measured entrainment for plumes generated without screens is generally greater than the entrainment for equivalent plumes with screens. The difference in entrainment tends to increase as $W_{o}$ decreases consistent with the relative increase in $W_{s}$ (as $W_{o}$ decreases) due to lateral spread of gases below the balcony. For the conditions studied, plumes generated without screens from a wide opening $\left(W_{o}=\right.$ $1.0 \mathrm{~m}$ ) tended to provide an increase in measured entrainment of approximately $10 \%$ compared to plumes with screens. Plumes generated without screens from a narrow opening $\left(W_{o}=0.2 \mathrm{~m}\right)$ tended to provide an increase in measured entrainment of approximately $80 \%$ compared to plumes with screens. The relative increase in entrainment measured in this work is specific to the breadth of balcony examined and is likely to vary for different balcony breadths. As the balcony breadth was fixed in this 
study, further work is desirable to examine plumes generated without screens for a variety of balcony breadths.

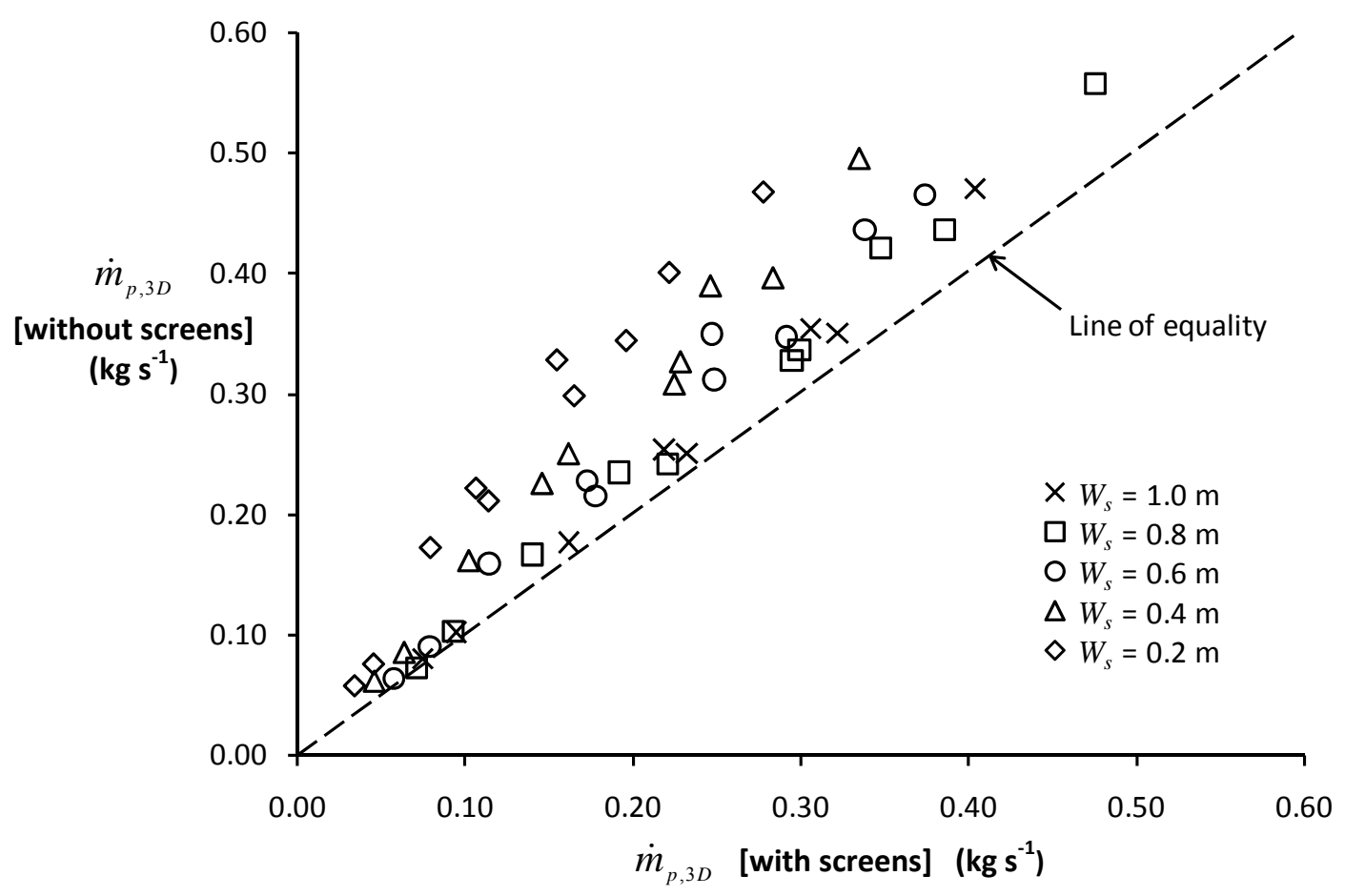

Figure 7: Comparison of $\dot{m}_{p, 3 D}$ for equivalent plumes with and without screens.

The nature of the flow below the spill edge without screens generally violates the fundamental assumption for spill plume calculation methods in terms of uniformity across the layer flow below the spill edge (i.e. in terms of depth and temperature). Therefore, an approximate solution to determine entrainment for this complex flow can be developed using a similar analysis to that carried out by Law [4] by using an effective lateral extent of the plume below the spill edge (i.e. $W_{e, s}$ ) within an entrainment design formula for a channelled balcony spill plume. This effective width does not represent the actual width of the flow below the spill edge, but is an effective property used to approximate entrainment for unchannelled flow. In this case it seems more appropriate to apply $W_{e, s}$ within the new design equation for the channelled balcony spill plume proposed by Harrison and Spearpoint [2] (Equation 1) as it is more general in nature than other methods. As the balcony breadth was not varied in this work, a robust general expression could not be developed without further work examining flows from a range of balcony breadths. This further work is currently in progress at the University of Canterbury. However the performance of the existing expression for $W_{e, s}$ as given by Law [4] is assessed (but for use within Equation 1), namely,

$W_{e, s}=W_{o}+b$

Although Equation 3 was determined from very few data points, it was empirically derived from flows with a variety of $b$ and is given in current design guidance $[5,6]$. Equation 3 implies a $27^{\circ}$ angle in the 
growth of the effective plume width across the breadth of the balcony on each side. Figure 8 shows a comparison between a line representing Equation 3 and the experimental data for each of the four heights of rise above the spill edge plotted in non-dimensional form using $W_{e, s,} W_{o}$ and $b$. Figure 8 shows that Equation 3 provides a reasonably good prediction of $W_{e, s} / W_{o}$ for $W_{o} / b \geq 2$. However, for $W_{o} / b<2$, Equation 3 significantly under predicts the required $W_{e, s} / W_{o}$. This is not surprising as Equation 3 was not developed from flows from very narrow openings. A better approximation to the data can be achieved if a greater angle of spread in the effective width of the plume is assumed. Equation 4 represents a $45^{\circ}$ angle in the growth of the effective plume width on each side.

$W_{e, s}=W_{o}+2 b$

Figure 8 shows that Equation 4 gives a better approximation to the data compared to Equation 3 for the range of $W_{d} / b$ examined, however, it is unclear if Equation 4 applies for a variety of $b$ which was not varied in this work. Therefore the analysis here primarily focuses on the performance of Equation 3 , which was developed from a variety of $b$ (albeit from very few data points), until further work is carried out. As Equation 3 provides a relationship to suitably describe $W_{e, s}$ for use within Equation 1 for flows where $W_{o} / b \geq 2$, the following formula is proposed as a simple approximation to predict entrainment for the 3-D balcony spill plume without channelling screens below the balcony, such that,

$\dot{m}_{p, 3 D, \text { unchan }}=0.16 \dot{Q}_{c}^{1 / 3}\left[\left(W_{o}+b\right)^{2 / 3}+1.56 d_{s}^{2 / 3}\right] z_{s}+1.34 \dot{m}_{s}$

with the strict limit that,

$\frac{W_{o}}{b} \geq 2$

Since the smoke flow behaviour of plumes generated without channelling screens is likely to be susceptible to factors such as internal air movement (particularly for stagnant smoke at the flow extremities) and local geometry effects (e.g. presence of downstands, upstands, etc) the entrainment analysis should ideally be supported by numerical modelling. Numerical modelling is recommended to predict entrainment into plumes generated from unchannelled flows where $W_{o} / b<2$ (at least until further experiments and analysis have been carried out) and Equation 3 should not be applied. An assessment of the performance of numerical modelling to predict plumes without channelling screens (using the experimental data from this study) is currently in progress at the University of Canterbury. The use of Equation 3 in existing guidance (e.g. references 5 and 6) should be treated with caution for unchannelled flows where $W_{o} / b<2$. 


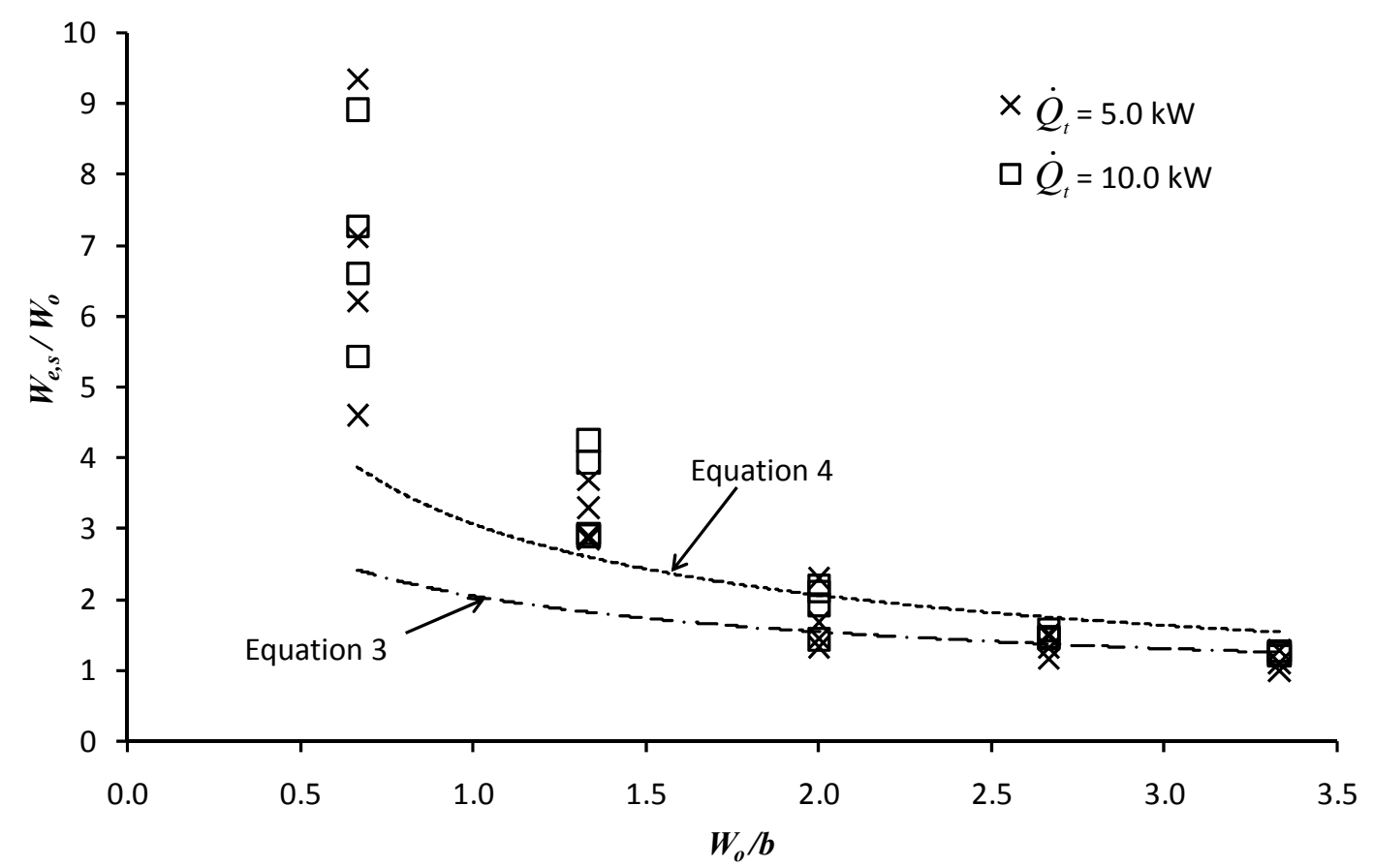

Figure 8: Plot of $W_{e, s} / W_{o}$ versus $W_{o} / b$ and comparison with Equation 3.

\section{CONCLUSIONS}

Plumes generated without channelling screens caused lateral spread of the layer flow below the balcony. This spread gave rise to plumes with a greater lateral extent above the spill edge compared to plumes with screens below the balcony. The amount of lateral spread is dependent upon the velocity of the flow from the fire compartment opening which increases when $W_{o}$ decreases and/or $\dot{Q}_{c}$ increases. There was also smoke contamination local to the area above the balcony in line with the fire compartment opening. The measured entrainment for plumes generated without screens was greater than that from equivalent plumes with screens. The difference in entrainment increased as $W_{o}$ decreased due to the spread of gases below the balcony.

The entrainment for unchannelled balcony spill plumes can be approximated by using an effective lateral extent of the plume below the spill edge using the following formula, such that,

$$
\dot{m}_{p, 3 D, \text { unchan }}=0.16 \dot{Q}_{c}^{1 / 3}\left[\left(W_{o}+b\right)^{2 / 3}+1.56 d_{s}^{2 / 3}\right] z_{s}+1.34 \dot{m}_{s}
$$

with the strict limit that,

$$
\frac{W_{o}}{b} \geq 2
$$

This is an approximate solution to a complex smoke flow and should be used in the early stages of design. Ideally, the entrainment analysis of these plumes should be supported by numerical modelling. 
Numerical modelling is recommended to predict entrainment into plumes where $W_{o} / b<2$, at least until further experiments and analysis has been carried out.

\section{ACKNOWLEDGEMENTS}

The authors would like to thank the following: Education New Zealand, for awarding the lead author a New Zealand International Doctoral Research Scholarship. The National Fire Protection Association for awarding the lead author the David B. Gratz Scholarship. Bob Wilsea-Smith and Grant Dunlop of the University of Canterbury, for their help with the design and construction of the experimental apparatus. The New Zealand Fire Service Commission for their continued support of the Fire Engineering programme at the University of Canterbury.

\section{NOMENCLATURE}

\section{Symbol}

$b$

$d$

$\dot{m}$

$\dot{Q}_{c}$

$\dot{Q}_{t}$

W

$Z_{s}$

$Z_{\text {trans }}$

\section{List of subscripts}

\section{e}

$O$

$p$

$S$

unchan

$3 D$

\section{Description}

Balcony breadth $(\mathrm{m})$

Depth of gas layer $(\mathrm{m})$

Mass flow rate of gases $\left(\mathrm{kgs}^{-1}\right)$

Convective heat flow of gases below the spill edge $(\mathrm{kW})$

Total heat output of the fire (kW)

Lateral extent of gas flow below the spill edge $(\mathrm{m})$

Height of rise of the plume from the spill edge (i.e. the balcony edge) to the smoke layer base in the reservoir $(\mathrm{m})$

Height of rise of the balcony spill plume where there is a transition in the rate of entrainment to that of an axisymmetric plume $(\mathrm{m})$

\section{Description}

An effective property

A property of the fire compartment opening

Variable evaluated in the plume at an arbitrary height of rise

Variable evaluated in the layer flow below the spill edge

A property of an unchannelled balcony spill plume

Property of the 3-D plume 


\section{REFERENCES}

1. Morgan H P, Ghosh B K, Garrad G, Pamlitschka R, De Smedt J-C, Schoonbaert LR. Design Methodologies for Smoke and Heat Exhaust Ventilation, BRE Report 368, Building Research Establishment, Watford, UK, 1999.

2. Harrison R, Spearpoint M. Characterisation of balcony spill plume entrainment using physical scale modelling. Proc. of the 9th Symposium of the International Association of Fire Safety Science, Karlsruhe, Germany, p. 727-738, 2008. doi: 10.3801/IAFSS.FSS.9-727

3. Hansell G O, Morgan H P, Marshall N R. Smoke Flow Experiments in a Model Atrium. Building Research Establishment Occasional Paper, OP 55, 1993.

4. Law M. Measurements of Balcony Smoke Flow. Fire Safety Journal, vol. 24, no.2, pp 189-195, 1995. doi: 10.1016/0379-7112(95)00011-H

5. Chartered Institution of Building Services Engineers, CIBSE Guide Volume E: Fire Engineering, London, CIBSE, 2003.

6. National Fire Protection Association. Smoke Management Systems in Malls, Atria and Large Areas (2009 edition). Publication No.92B. Quincy, MA, 2009.

7. Lougheed G D, McCartney C J, Gibbs E. Balcony Spill Plumes. Final Research Project Report 1247. National Research Council, Canada, 2006.

8. Thomas P H, Hinkley P L, Theobald C R, Simms D L. Investigations into the Flow of Hot Gases in Roof Venting. Fire Research Technical Paper No 7, London, The Stationary Office, 1963.

9. Marshall N R. The Behaviour of Hot Gases Flowing within a Staircase. Fire Safety Journal, vol. 9, no. 3, 1985, pp 245-255. doi: 10.1016/0379-7112(85)90035-9

10. Klote J H and Milke J A. Principles of Smoke Management. American Society of Heating, Refrigerating and Air-conditioning Engineers, Atlanta, GA, 2002.

11. Harrison R. Entrainment of Air into Thermal Spill Plumes. Doctor of Philosophy in Fire Engineering, University of Canterbury, New Zealand, 2009. 